\title{
Protective Effects of Nicotine Against Aminochrome-Induced Toxicity in Substantia Nigra Derived Cells: Implications for Parkinson's Disease
}

\author{
Patricia Muñoz, \\ Department of Molecular \& Clinical Pharmacology, Faculty of Medicine, ICBM, University of Chile, \\ Santiago, Chile
}

Sandro Huenchuguala,

Department of Molecular \& Clinical Pharmacology, Faculty of Medicine, ICBM, University of Chile, Santiago, Chile

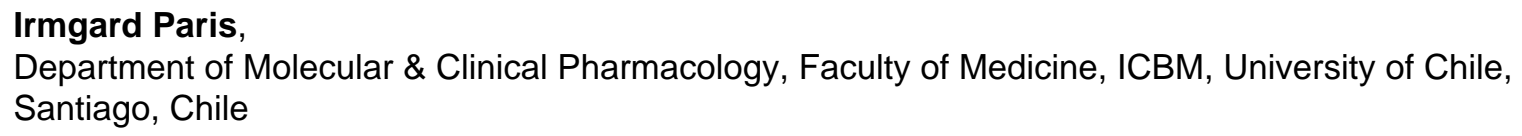

Carlos Cuevas,

Department of Molecular \& Clinical Pharmacology, Faculty of Medicine, ICBM, University of Chile, Santiago, Chile

\section{Monica Villa,}

Department of Molecular \& Clinical Pharmacology, Faculty of Medicine, ICBM, University of Chile, Santiago, Chile

\section{Pablo Caviedes,}

Department of Molecular \& Clinical Pharmacology, Faculty of Medicine, ICBM, University of Chile, Santiago, Chile

Juan Segura-Aguilar, and

Department of Molecular \& Clinical Pharmacology, Faculty of Medicine, ICBM, University of Chile, Santiago, Chile

\section{Yousef Tizabi}

Department of Pharmacology, Howard University College of Medicine, 520 W Street NW, Washington, DC 20059, USA

\section{Abstract}

\begin{abstract}
Parkinson's disease is a debilitating progressive neurodegenerative disorder that results from the loss of or damage to dopaminergic cells containing neuromelanin in the substantia nigra (SN). The underlying neurodegenerative mechanism(s), however, remain elusive. Aminochrome, the precursor of neuromelanin is an endogenous substance capable of inducing selective neurotoxicity to dopaminergic neurons in SN. Nicotine, on the other hand, may offer protective effects against dopaminergic cell damage induced by various neurotoxins including MPTP and salsolinol. In this study, we sought to determine whether nicotine may also protect against aminochrome-induced toxicity in SN derived RCSN-3 cells. Exposure of RCSN-3 cells to a combination of aminochrome $(50 \mu \mathrm{M})$ and dicoumarol $(50 \mu \mathrm{M})$ for $48 \mathrm{~h}$ induced approximately $70 \%$ cell death. Pretreatment
\end{abstract}

\footnotetext{
(C) Springer Science+Business Media, LLC 2012

Correspondence to: Yousef Tizabi.

Y. Tizabi ytizabi@howard.edu.
} 
with nicotine, dose-dependently blocked this toxicity. The effects of nicotine in turn were dosedependently blocked by mecamylamine, a non-selective nicotinic receptor antagonist. These results suggest involvement of nicotinic receptors in protective effects of nicotine against aminochrome-induced toxicity and provide further evidence for possible therapeutic effects of nicotine or nicotinic agonists in Parkinson's disease.

\section{Keywords}

Aminochrome; Nicotine; RCSN-3 Cells; Neurotoxicity; Neuroprotection; Parkinson's disease

Considerable effort is dedicated towards development of novel pharmacotherapies for Parkinson's disease (PD) and understanding the cellular and molecular mechanisms leading to selective neurodegeneration of dopaminergic neurons containing neuromelanin in substantia nigra ( $\mathrm{SN}$ ) that are responsible for motor symptoms in PD. Although, the molecular basis of such neurodegeneration remains unclear, it is generally accepted that various mechanisms including mitochondrial dysfunction, aggregation of proteins such as alpha-synuclein, dysfunction of protein degradation systems, oxidative stress, and neuroinflammation can be major contributory factors (Dehay and Bezard 2011; Schapira and Jenner 2011). Various in vivo and in vitro models have been developed to facilitate screening compounds or to understand the cellular/molecular mechanisms responsible for dopaminergic deficiency associated with nigro-striatal pathway. However, majority of these studies utilize neurotoxins that: (i) are of exogenous origin, (ii) induce extensive acute cell death (e.g. MPTP induces severe Parkinson symptoms in only few days while PD degeneration occurs over years, and (iii) each neurotoxin may induce damage by a different mechanism (Paris et al.2007). In this study we used aminochrome which is produced endogenously during dopamine oxidation and is the precursor of neuromelanin.

Aminochrome is involved in nearly all mechanisms that are proposed to be involved in the degenerative process in PD including (i) mitochondria dysfunction (Van Laar et al. 2009; Aguirre et al. 2012; Muñoz et al. 2012), (ii) aggregation of proteins such as alpha-synuclein (Norris et al. 2005) or actin causing disruption of cytoskeleton and axonal transport (Paris et al.2010), (iii) protein degradation dysfunction (due to inactivation of the proteasomal system when aminochrome forms adducts with Parkin, a ubiquitin ligase (LaVoie et al.2005) or inhibiting the fusion between autophagy vacuoles and lysosomes by forming adducts with beta-tubulin (Paris et al. 2010, 2011), and (iv) oxidative stress where aminochrome is reduced by one-electron to leukoaminochrome o-semiquinone radical resulting in generation of superoxide radicals, hydrogen peroxide and hydroxyl radicals (Arriagada et al. 2004).

Nicotine, on the other hand, has been shown to offer protective effects against dopaminergic cell damage induced by various neurotoxins including MPTP and salsolinol (Copeland et al. 2005, 2007; Quik et al. 2008; Ramlochansingh et al. 2011). Here, we were interested in determining whether nicotine may also protect against aminochrome-induced toxicity and if so, whether this action is mediated through nicotinic receptors.

For this purpose we utilized RCSN-3 cells, a cell line derived from rat SN with catecholaminergic features including synthesis and release of dopamine, expression of VMAT-2, dopamine, norepinephrine and serotonin transporter as well as production of neuromelanin (Paris et al.2008). RCSN-3 cells grow in monolayer with a doubling time of $52 \mathrm{~h}$ at a plating efficiency of $21 \%$ and a saturation density of $56,000 \mathrm{cells} / \mathrm{cm}^{2}$ when kept in normal growth media composed of: DME/HAM-F12 (1:1), $10 \%$ bovine serum, $2.5 \%$ fetal bovine serum, $40 \mathrm{mg} / \mathrm{l}$ gentamicine sulfate (Arriagada et al. 2004; Paris et al. 2008, 2010; Muñoz et al. 2012). Cultures were kept in an incubator at $37^{\circ} \mathrm{C}$ with $100 \%$ humidity and an atmosphere of $10 \% \mathrm{CO}_{2}$. RCSN-3 cells in passage 8-10 were exposed to a 
combination of aminochrome and dicoumarol (Sigma Chemical Co., St Louis. MO. USA) to induce maximal cell damage during the $48 \mathrm{~h}$ incubation. The concentrations used here were based on previous studies using the same cell line (Paris et al. 2010,2011). Aminochrome was synthesized by oxidizing dopamine with tyrosinase in buffer $20 \mathrm{mM}$ MES at pH 6.0 for $15 \mathrm{~min}$ at room temperature as described by Paris et al.2010. Dicoumarol $\left(10^{-2} \mathrm{M}\right)$ was dissolved in $0.1 \mathrm{~N} \mathrm{NaOH}$ and diluted $\left(10^{-3} \mathrm{M}\right)$ directly in distilled water. Cell death was measured by counting live and dead cells with flow cytometry after staining with $0.5 \mu \mathrm{M}$ calcein AM and $5 \mu \mathrm{M}$ ethidium homodimer- 1 for $45 \mathrm{~min}$ at $37^{\circ} \mathrm{C}$, using $510-560 \mathrm{~nm}$ (excitation) and LP-590 nm (emission) for ethidium homodimer-1 and 450-490 nm (excitation) and 515-565 nm (emission) for Calcein AM. Dicoumarol is an inhibitor of diaphorase, the enzyme involved in protection against aminochrome (Arriagada et al. 2004; Paris et al.2010). Cells were pretreated with various concentrations of nicotine prior to such combination. Once the protective effects of nicotine were established, various concentrations of mecamylamine, a non-selective nicotinic receptor antagonist were applied prior to nicotine to determine the extent of nicotinic receptor involvement in neuroprotective effects of nicotine. The concentrations of nicotine and mecamylamine (both purchased from Sigma, St. Louis, MO) were based on previous studies using these agents in similar in vitro studies (Copeland et al. 2005; Ramlochansingh et al.2011). All data $(n=5)$ are expressed as mean \pm SEM. The statistical significance was assessed using analysis of variance (1-way ANOVA) followed by Tukey's post hoc test. Significance was set a priori at $p<0.05$.

Figure 1 shows toxicity induced by aminochrome (AM) is significantly enhanced by addition of dicoumarol (DIC). Whereas $50 \mu \mathrm{M}$ aminochrome alone resulted in approximately $35 \%$ toxicity, addition of $50 \mu \mathrm{M}$ dicoumarol (which had no effect of its own) increased the toxicity to approximately $70 \%$. Hence this combination was used in subsequent experiments to determine the protective effects of nicotine.

Figure 2 shows dose-dependent protective effects of nicotine against AM + DIC. Nicotine at $20 \mu \mathrm{M}$ concentration totally blocked the toxicity induced by AM + DIC. Nicotine at concentrations used (1-20 $\mu \mathrm{M}$ ) had no effect of its own on cell viability (data not shown). Moreover, in an initial study it was shown that nicotine also significantly attenuated the modest toxicity induced by aminochrome only.

Figure 3 shows the effects of various concentrations of mecamylamine alone on cellular toxicity. Mecamylamine at 5 and 10 micormolar (uM) concentrations did not have any effect of its own on cellular toxicity. However, at concentrations of 50 and $100 \mu \mathrm{M}$ resulted in significant toxicity ( 25 and $30 \%$, respectively). Hence the lower non-toxic doses of mecamylamine were used to block nicotine's effect.

Figure 4 shows that mecamylamine dose-dependently blocked the protective effects of nicotine against AM + DIC. At $5 \mu \mathrm{M}$, mecamylamine partially blocked nicotine's effect. However, at $10 \mu \mathrm{M}$, mecamylamine completely blocked the effect of nicotine.

It is likely that loss of dopaminergic neurons containing neuromelanin in PD involves aminochrome neurotoxicity as this metabolite of dopamine oxidation has been implicated in practically all mechanisms proposed to be related to neurodegeneration of dopaminergic neurons including mitochondria dysfunction, protein aggregation, dysfuntion of protein degradation and oxidative stress (Segura-Aguilar et al. 1998; LaVoie et al. 2005; Norris et al. 2005; Zafar et al. 2006; Van Laar et al. 2009; Paris et al. 2010; Aguirre et al. 2012; Muñoz et al. 2012). That nicotine can protect against such toxicity provides further evidence for possible usefulness of nicotine or nicotinic agonists as a therapeutic intervention, particularly in prevention or slowing the progression of PD. This contention is also 
supported by our findings that the effects of nicotine could be blocked by the nicotinic receptor antagonist, mecamylamine.

Various in vitro and in vivo studies have shown protective effects of nicotine against various toxicants, including those selectively targeting dopaminergic neurons. Thus, nicotine blocked salsolinol-induced toxicity in SH-SY5Y cells (Copeland et al. 2005,2007;

Ramlochansingh et al. 2011) as well as MPTP-induced cell damage in non-human primates (Quik et al. 2008). Although the effects of nicotine are primarily mediated through the central nicotinic receptors, the exact nicotinic receptor subtype involvement in these protective effects of nicotine has yet to be determined. It was shown that at least in SHSY5Y cells which are human neuroblastoma derived cells, the effects of nicotine are mediated by alpha3 and/or alpha6 containing subtypes (Copeland et al. 2007).

The damaging effects of various toxicants could be mediated through apoptotic, necrotic or a combination of the two. These processes could in turn be brought about through abnormal protein folding or protein accumulation (e.g. alpha-synuclein, actin, tubulin, etc.), mitochondrial damage via oxidative stress or free radical formation. It is intriguing that some of these processes could be the result of normal metabolic pathways associated with the critical neurotransmitter (e.g. dopamine). Hence, it would be of significant interest to determine the underlying mechanisms involved in aminochrome-induced toxicity and how nicotinic system specifically interacts with such processes. In this regard, it is of interest to note that some in vitro studies suggest an anti-apoptotic effect of nicotine (Copeland et al. 2007; Ramlochansingh et al. 2011).

Since the etiology of PD remains elusive and many factors might be involved, a more comprehensive therapy might entail combination of drugs that target various aspects of the disease. Thus, nicotine or nicotinic agonists may also be useful as adjunct therapy with currently used drugs. Interestingly, it was shown that a combination of nicotine with donepezil, a cholinesterase inhibitor, used primarily in Alzheimer's disease, provided an additive protection against salsolinol-induced toxicity in SH-SY5Y cells (Das and Tizabi 2009).

In summary, our results indicate a protective effect of nicotine against aminochromeinduced toxicity in RCN-3 dopaminergic cells which is mediated by nicotinic receptors. These findings provide further support for usefulness of nicotinic interventions in PD. Further investigation on the mechanism of this neuroprotection is warranted.

\section{Acknowledgments}

This study was supported by FONDECYT \#1100165 (JSA), NIH/NIGMS (2SO6 GM08016-39 (YT), and NIHRCMI 2 G12 RR003048 (YT).

\section{References}

Aguirre P, Urrutia P, Tapia V, Villa M, Paris I, Segura-Aguilar J, Núñez MT. The dopamine metabolite aminochrome inhibits mitochondrial complex I and modifies the expression of iron transporters DMT1 and FPN1. Biometals. 2012 (Epub ahead of print).

Arriagada C, Paris I, Sanchez de las Matas MJ, Martinez-Alvarado P, Cardenas S, Castañeda P, Graumann R, Perez-Pastene C, Olea-Azar C, Couve E, Herrero MT, Caviedes P, Segura-Aguilar J. On the neurotoxicity mechanism of leukoaminochrome o-semiquinone radical derived from dopamine oxidation: mitochondria damage, necrosis, and hydroxyl radical formation. Neurobiol Dis. 2004; 16:468-477. [PubMed: 15193303] 
Copeland RL Jr, Leggett YA, Kanaan YM, Taylor RE, Tizabi Y. Neuroprotective effects of nicotine against salsolinol-induced cytotoxicity: implications for Parkinson's disease. Neurotox Res. 2005; 8:289-293. [PubMed: 16371323]

Copeland RL Jr, Das JR, Kanaan YM, Taylor RE, Tizabi Y. Antiapoptotic effects of nicotine in its protection against salsolinol-induced cytotoxicity. Neurotox Res. 2007; 12:61-69. [PubMed: 17513200]

Das JR, Tizabi Y. Additive protective effects of donepezil and nicotine against salsolinol-induced cytotoxicity in SH-SY5Y cells. Neurotox Res. 2009; 16:194-204. [PubMed: 19526284]

Dehay B, Bezard E. New animal models of Parkinson's disease. Mov Disord. 2011; 26:1198-1205. [PubMed: 22046592]

LaVoie MJ, Ostaszewski BL, Weihofen A, Schlossmacher MG, Selkoe DJ. Dopamine covalently modifies and functionally inactivates parkin. Nat Med. 2005; 11:1159-1161. [PubMed: 16270070]

Muñoz P, Paris I, Sanders LH, Greenamyre JT, Segura-Aguilar J. Over expression of VMAT-2 and DT-diaphorase protect susbtantia nigra-derived cells against aminochrome neurotoxicity. Biochim Biophys Acta. 2012 (Epub ahead of print).

Norris EH, Giasson BI, Hodara R, Xu S, Trojanowski JQ, Ischiropoulos H, Lee VM. Reversible inhibition of alpha-synuclein fibrillization by dopaminochrome-mediated conformational alterations. J Biol Chem. 2005; 280:21212-21219. [PubMed: 15817478]

Paris I, Cardenas S, Lozano J, Perez-Pastene C, Graumann R, Riveros A, Caviedes P, Segura-Aguilar J. Aminochrome as a preclinical experimental model to study degeneration of dopaminergic neurons in Parkinson's disease. Neurotox Res. 2007; 12:125-134. [PubMed: 17967736]

Paris I, Lozano J, Cardenas S, Perez-Pastene C, Saud K, Fuentes P, Caviedes P, Dagnino-Subiabre A, Raisman-Vozari R, Shimahara T, Kostrzewa JP, Chi D, Kostrzewa RM, Caviedes R, SeguraAguilar J. The catecholaminergic RCSN-3 cell line: a model to study dopamine metabolism. Neurotox Res. 2008; 13:221-230. [PubMed: 18522901]

Paris I, Perez-Pastene C, Cardenas S, Iturriaga-Vasquez P, Muñoz P, Couve E, Caviedes P, SeguraAguilar J. Aminochrome induces disruption of actin, alpha-, and beta-tubulin cytoskeleton networks in substantia-nigra-derived cell line. Neurotox Res. 2010; 18:82-92. [PubMed: 20087799]

Paris I, Muñoz P, Huenchuguala S, Couve E, Sanders LH, Greenamyre JT, Caviedes P, SeguraAguilar J. Autophagy protects against aminochrome-induced cell death in substantia nigra-derived cell line. Toxicol Sci. 2011; 121:376-388. [PubMed: 21427056]

Quik M, O'Leary K, Tanner CM. Nicotine and Parkinson's disease: implications for therapy. Mov Disord. 2008; 23:1641-1652. [PubMed: 18683238]

Ramlochansingh C, Taylor RE, Tizabi Y. Toxic effects of low alcohol and nicotine combinations in SH-SY5Y cells are apoptotically mediated. Neurotox Res. 2011; 20:263-269. [PubMed: 21222065]

Schapira AH, Jenner P. Etiology and pathogenesis of Parkinson's disease. Mov Disord. 2011; 26:1049-1055. [PubMed: 21626550]

Segura-Aguilar J, Metodiewa D, Welch C. Metabolic activation of dopamine $o$-quinones to $o$ semiquinones by NADPH cytochrome P450 reductase may play an important role in oxidative stress and apoptotic effects. Biochim Biophys Acta. 1998; 1381:1-6. [PubMed: 9659366]

Van Laar VS, Mishizen AJ, Cascio M, Hastings TG. Proteomic identification of dopamine-conjugated proteins from isolated rat brain mitochondria and SH-SY5Y cells. Neurobiol Dis. 2009; 34:487500. [PubMed: 19332121]

Zafar KS, Siegel D, Ross D. A potential role for cyclized quinones derived from dopamine, DOPA, and 3,4-dihydroxy-phenylacetic acid in proteasomal inhibition. Mol Pharmacol. 2006; 70:10791086. [PubMed: 16790533] 


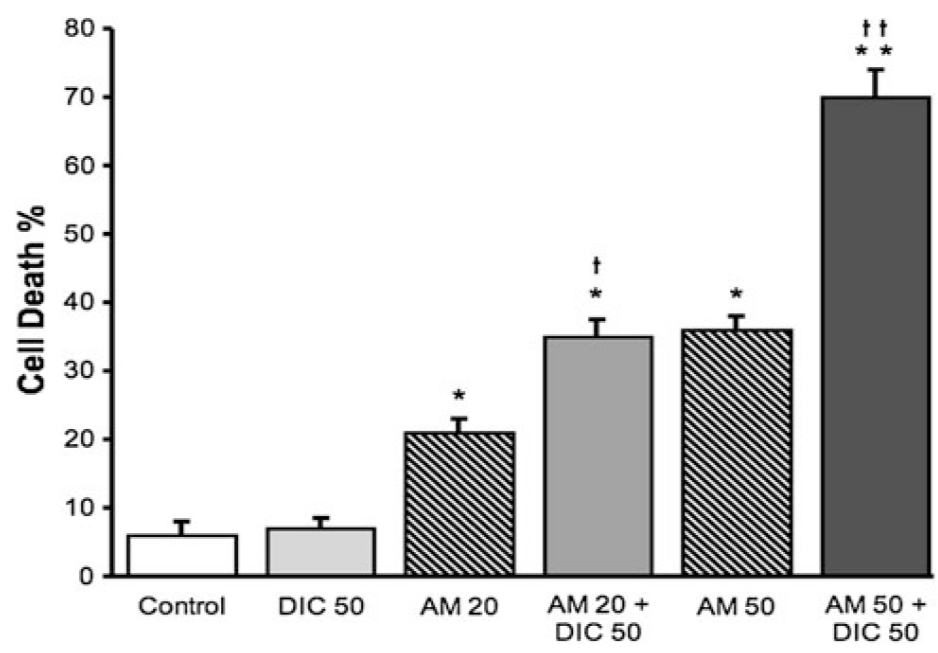

Fig. 1.

Effects for various concentrations of aminochrome (AM) $(20$ and $50 \mu \mathrm{M})$ with and without dicoumarol (DIC) $(50 \mu \mathrm{M})$ on $\%$ cell death in RCSN-3 cells. Cells were incubated for $48 \mathrm{~h}$. Values are mean \pm SEM of five independent experiments $* p<0.05$, ** $p<0.01$ compared to control, ${ }^{\dagger} p<0.05,{ }^{\dagger \dagger} p<0.01$ compared to AM only 


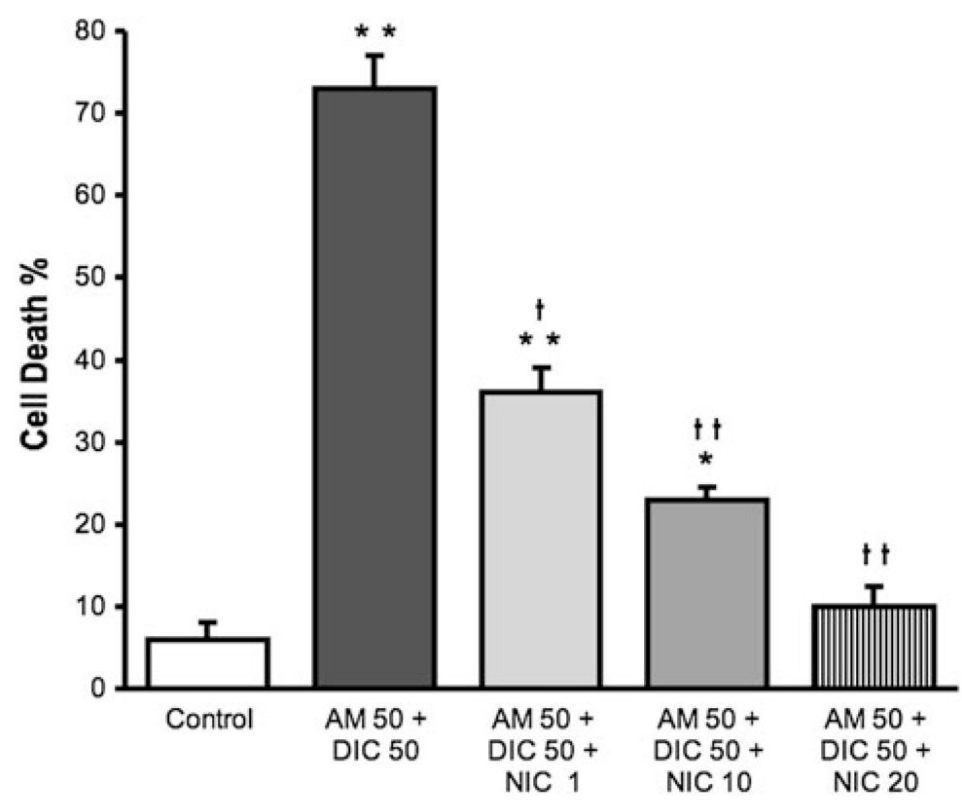

Fig. 2.

Effects for various concentrations of nicotine (NIC) $(1-20 \mu \mathrm{M})$ on toxicity induced by the combination of aminochrome (AM, $50 \mu \mathrm{M})$ and dicoumarol (DIC, $50 \mu \mathrm{M}$ ) in RCSN-3 cells. Nicotine was added $1 \mathrm{~h}$ before the combination of AM + DIC. Cells were incubated for $48 \mathrm{~h}$. Values are mean \pm SEM of five independent experiments $* p<0.05, * * p<0.01$ compared to control, ${ }^{\dagger} p<0.05,{ }^{\dagger \dagger} p<0.01$ compared to AM + DIC 


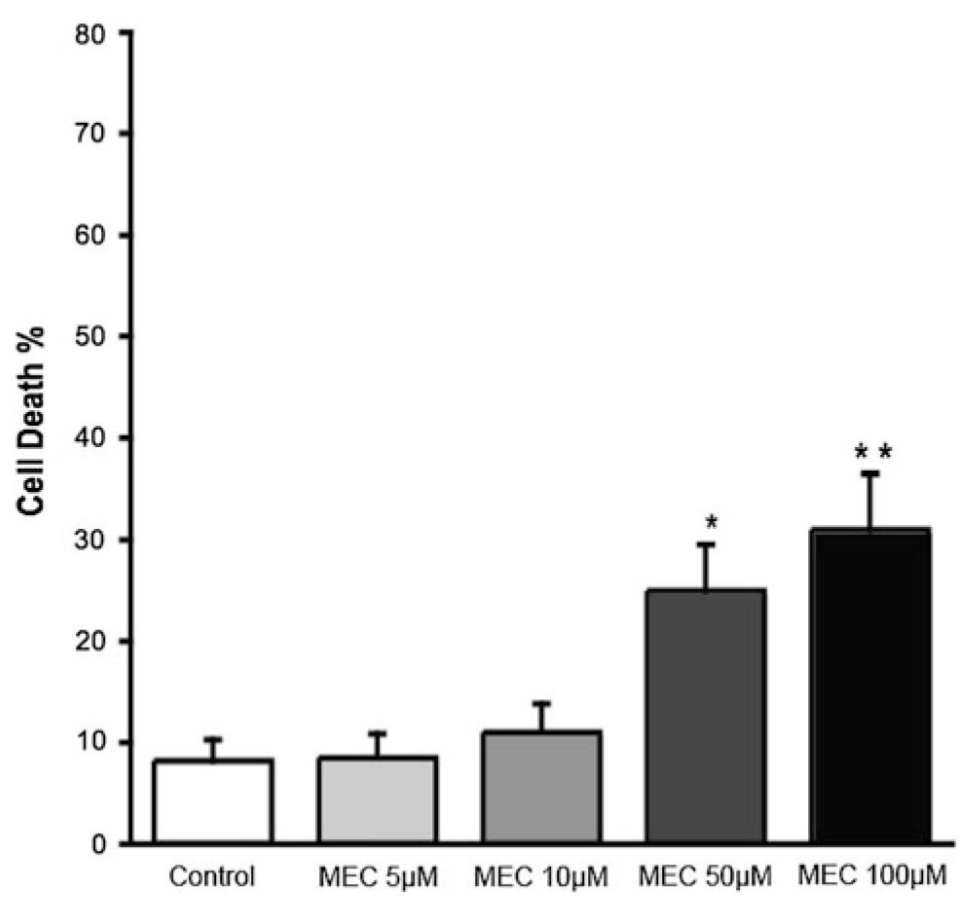

Fig. 3.

Effects for various concentrations of mecamylamine (MEC, 5-100 $\mu \mathrm{M}$ ) on RCSN-3 cells. Cells were incubated for $48 \mathrm{~h}$. Values are mean \pm SEM of five independent experiments. ${ }^{*} p$ $<0.05, * * p<0.01$ compared to control 




Fig. 4.

Effects for various concentrations of mecamylamine (MEC, 5 and $10 \mu \mathrm{M}$ ) on protective effects of nicotine (NIC) $(20 \mu \mathrm{M})$ on toxicity induced by the combination of aminochrome $(\mathrm{AM}, 50 \mu \mathrm{M})$ ) and dicoumarol (DIC, $50 \mu \mathrm{M}$ ) in RCSN-3 cells. Mecamylamine was added 1 $\mathrm{h}$ before nicotine which was added $1 \mathrm{~h}$ before the combination of AM + DIC. Cells were incubated for $48 \mathrm{~h}$. Values are mean \pm SEM of five independent experiments $* * p<0.01$ compared to control, ${ }^{\dagger} p<0.05,{ }^{\dagger \dagger} p<0.01$ compared to AM + DIC ${ }^{\#} p<0.05,{ }^{\# \#} p<0.01$ compared to AM + DIC + NIC 